\title{
Estimation of Degradation Characteristics of Organic Matter and Nitrification Conditions in the Sequencing Batch Reactor using Oxygen Uptake Rate
}

\author{
YOSHINORI SATO and MINORU NAGASAKA \\ Department of Materials Science, Faculty of Engineering, Ibaraki University \\ /4-12-1, Nakanarusawa-cho, Hitachi, Ibaraki, 316-8511, Japan
}

\begin{abstract}
In this study, a method for estimating degradation characteristics of organic matter and nitrification conditions in the sequencing batch reactor (SBR) was investigated by measuring oxygen uptake rate (OUR). The experiments were carried out by changing the ratio of the influent fed in the SBR. The influent used for the experiment was collected from a separated-type sewage-treatment plant, where mainly domestic wastewater has been treated. Two kinds of OURs : total oxygen uptake rate (TOUR) and carbonaceous oxygen uptake rate (COUR) were measured simultaneously. The COUR was measured in the presence of allylthiourea as a nitrification inhibitor. Nitrogenous oxygen uptake rate (NOUR) was calculated by subtracting COUR from TOUR. It is suggested that the measurement of COUR could be used to estimate the concentration of TOC in the supernatant of the mixed liquor in the SBR. The application of NOUR was found to be very effective for examining the presence of $\mathrm{NH}_{4}-\mathrm{N}$ in the effluent. Thus the degradation characteristics of organic matter and the nitrification conditions in the SBR could be analyzed by measuring both COUR and NOUR.
\end{abstract}

Key words : activated sludge, sequencing batch reactor, nitrification, denitrification, oxygen uptake rate, allylthiourea

\section{INTRODUCTION}

The standard activated sludge process is used for removing only organic matter. An advanced wastewater treatment process for biological removal of nitrogen and phosphorus has been developed in order to prevent eutrophication. Anaerobic, anoxic, and oxic processes are required for biological removal of nitrogen and phosphorus.

Biological removal of nitrogen consists of nitrification and denitrification. For nitrification, first nitrite bacteria oxidize $\mathrm{NH}_{4}-\mathrm{N}$ to $\mathrm{NO}_{2}-\mathrm{N}$ under the oxic condition. In the second step, $\mathrm{NO}_{2}-\mathrm{N}$ is oxidized to $\mathrm{NO}_{3}-\mathrm{N}$ by nitrate bacteria. The denitrification occurs in nitrite or nitrate respiration under the action of denitrifying bacteria which produce $\mathrm{N}_{2}$ at the anoxic condition. Therefore, nitrification is necessary in order to carry out biological removal of nitrogen. In the oxic process during which nitrification can occur, oxidation degradation of organic matter also takes place. The amount of oxygen supplied in the reactor is very important for promoting the reaction. Therefore, the concentration of organic matter influences biological removal of nitrogen.

The sequencing batch reactor (SBR) process is one of many techniques for wastewater treatment. In this process, the SBR functions as a reactor and a final settling tank. The construction cost of the facility using the SBR is usually low, because no facility for 
return sludge is required. Also, the SBR can be easily maintained. The SBR can be applied to advanced wastewater treatment process for biological removal of nitrogen and/or phosphorus under appropriate operational control. The wastewater treatment facility using the SBR can be automated easily, since the anaerobic, anoxic, and oxic processes can be controlled by using various equipments such as personal computers. Therefore, the SBR seems to play a substantial role in the small-scale wastewater treatment plants.

For the advanced wastewater treatment process, $\mathrm{pH}, \mathrm{ORP}$, and DO meters are used as comparatively low-cost control equipments in the SBR. By using these equipments, however, it is difficult to accurately estimate the concentration of organic matter and actual degree of nitrification occurring in the SBR.

It was reported that biodegradable quantity of organic matter was measured using oxygen uptake rate (OUR) and empirical equations were proposed for the experimental results ${ }^{1-3)}$. In addition, the works which utilized OUR for the estimation of removal of organic matter and nitrification were also reported ${ }^{4-8)}$. Surmcz-Gorska et $a l .{ }^{9)}$ monitored the nitrification by a method measuring OUR in the presence of $\mathrm{NaClO}_{3}$ and allylthiourea, which act as inhibitors for Nirobactor and Nitrosomonas, respectively.

Based on these reports, the purpose of this study was to estimate the degradation characteristics of organic matter and the nitrification conditions by measuring OUR in the SBR at the stage when nitrification was completed. The degradation characteristics of organic matter and the nitrification conditions in the SBR were carefully examined, and then OURs for these characteristics were measured. A method to evaluate three kinds of OURs was proposed. Two kinds of OURs : total oxygen uptake rate (TOUR) and carbonaceous oxygen uptake rate (COUR) in the process of the treatment were measured simultaneously. TOUR included respiration of both heterotrophic and autotrophic bacteria. On the other hand, COUR was obtained by suppressing respiration of autotrophic bacteria in the presence of allylthiourea which act as a nitrification inhibitor. The nitrogenous oxygen uptake rate (NOUR) necessary for respiration of autotrophic bacteria was calculated by subtracting COUR from TOUR. A new method for estimating the degradation characteristics of organic matter and the nitrification conditions was thus established from both COUR and NOUR.

\section{MATERIALS AND METHODS}

Operational conditions A fill and draw type SBR with an effective volume of $10 l$ was used as the reactor. The experiments were carried out in the anoxic-oxic process. One cycle of the process took 8 hours, and the running of three cycles per day was continuously carried out. The activated sludge was acclimated under following conditions. The ratio of the influent fed per one cycle in the SBR was set at $33 \%$ and the water temperature was kept at $25^{\circ} \mathrm{C}$. The biomass was intermittently adjusted so that the mixed liquor suspended solids (MLSS) would be at the level of $2500 \mathrm{mg} / l$. Through the anoxicoxic process, the mixture was mechanically stirred at the rate of $80 \mathrm{rpm}$. The flow rate of air was adjusted every day so that $\mathrm{NH}_{4}-\mathrm{N}$ was not detected at the end of the oxic process. The concentration of dissolved oxygen (DO) at the final stage of the oxic process was usually $2-3 \mathrm{mg} / l$. Feeding of the influent and subsequent drawing of the effluent in the SBR were carried out within about 10 min using a pump. The influent used for the experiment was collected from the separated-type sewage-treatment plant in Hitachi City, where mainly domestic wastewater is treated. The qualities of the influent are listed in Table 1.

One cycle for five Runs in the SBR is shown in Fig. 1. In Run 1, the ratio of the influent fed for one cycle was set at $33 \%$, and Run 1 was defined as the control system. Runs 2-5 were the experimental systems. Using the activated sludge acclimated under the control system, the ratio of the influent fed in the SBR was temporarily increased for only one cycle in the experimental system. The ratios of the influent fed for Runs 2 and 4 were temporarily increased to $50 \%$ and $67 \%$, respectively. The flow rate of air was maintained constant when the influent was increased. Therefore, the oxic process took a longer time until $\mathrm{NH}_{4}-\mathrm{N}$ 
Table 1 Qualities of influent

\begin{tabular}{ccccccccccccc}
\hline $\begin{array}{c}\text { Run } \\
\text { No. }\end{array}$ & $\begin{array}{c}\mathrm{pH} \\
{[-]}\end{array}$ & $\begin{array}{c}\mathrm{SS} \\
{[\mathrm{mg} / l]}\end{array}$ & $\begin{array}{c}\mathrm{COD} \\
{[\mathrm{mg} / l]}\end{array}$ & $\begin{array}{c}\mathrm{BOD} \\
{[\mathrm{mg} / l]}\end{array}$ & $\begin{array}{c}\mathrm{TOC} \\
{[\mathrm{mg} / l]}\end{array}$ & $\begin{array}{c}\text { Alkalinity } \\
{[\mathrm{mg} / l]}\end{array}$ & $\begin{array}{c}\mathrm{T}-\mathrm{N} \\
{[\mathrm{mg} / l]}\end{array}$ & $\begin{array}{c}\mathrm{NH}_{4}-\mathrm{N} \\
{[\mathrm{mg} / l]}\end{array}$ & $\begin{array}{c}\mathrm{NO}_{2}-\mathrm{N} \\
{[\mathrm{mg} / l]}\end{array}$ & $\begin{array}{c}\mathrm{NO}_{3}-\mathrm{N} \\
{[\mathrm{mg} / l]}\end{array}$ & $\begin{array}{c}\mathrm{T}-\mathrm{P} \\
{[\mathrm{mg} / l]}\end{array}$ & $\begin{array}{c}\mathrm{PO}_{4}-\mathrm{P} \\
{[\mathrm{mg} / l]}\end{array}$ \\
\hline 1 & 7.40 & 39.8 & 60.0 & 201 & 45.2 & 149 & 27.4 & 22.2 & 0.10 & 0.10 & 3.1 & 1.8 \\
2 & 7.75 & 63.8 & 75.3 & 177 & 59.6 & 167 & 39.5 & 25.6 & $\mathrm{ND}$ & 0.05 & 4.1 & 1.8 \\
3 & 7.64 & 60.0 & 73.3 & 175 & 63.3 & 150 & 38.7 & 28.9 & $\mathrm{ND}$ & 0.07 & 4.3 & 2.2 \\
4 & 7.19 & 41.8 & 47.8 & 166 & 42.1 & 131 & 25.4 & 19.6 & 0.30 & 0.20 & 2.8 & 1.3 \\
5 & 7.31 & 40.4 & 59.7 & 126 & 42.2 & 145 & 25.2 & 21.2 & $\mathrm{ND}$ & $\mathrm{ND}$ & 2.9 & 1.5 \\
\hline
\end{tabular}

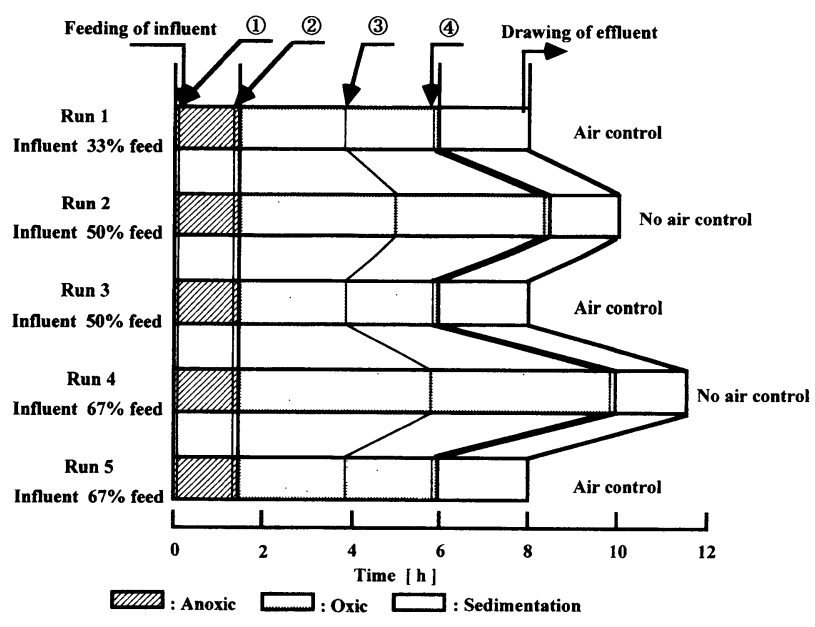

(1), (2), (3) and (4) : Measurement points of OUR

Fig. 1 Schematic of the cycle in the SBR for different runs.

was not detected. Although the ratios of the influent fed for Runs 3 and 5 were $50 \%$ and $67 \%$, respectively, the flow rate of air was adjusted so that the nitrification could be completed within the same time, $4.5 \mathrm{~h}$, in the same way as the oxic process in the control system.

The segmentation and decomposition of the activated sludge may occur under a very strong aeration. On the other hand, when the aeration is insufficient, the quality of the effluent is deteriorated, because the degradation of organic matter is insufficient and the activated sludge is spoiled. Therefore, the flow rate of air was controlled to be equal to or to surpass slightly the OUR of the activated sludge.

The total rate of respiration of heterotrophic and autotrophic bacteria is termed
TOUR. The unit of TOUR was represented as the oxygen utilized per unit volume and unit hour. By dividing this TOUR by the MLSS, the rate of oxygen utilized for $1 \mathrm{~g}$ of the activated sludge was obtained. Therefore, the flow rate of air was appropriately controlled by measuring OUR as reported by Suescun et $a l .^{10)}$.

The measurement of OUR for the activated sludge was carried out in a $100 \mathrm{~m} l$-culture bottle for measuring BOD. However, when DO was low, it was necessary to aerate the supernatant in a short time in order to get a value above $5 \mathrm{mg}-\mathrm{O} / \mathrm{l}$. The value of TOUR was obtained by measuring the change of DO with time in the culture bottle. In addition, the value of COUR was obtained in the presence of allylthiourea (ATU) for the method as described above. The concentration of ATU added in the culture bottle was $5 \mathrm{mg} / l$. The measurements of TOUR and COUR were carried out simultaneously. The value of NOUR was calculated from the difference between TOUR and COUR. The measurements of TOUR and COUR were carried out using the activated sludge obtained at four points of the initial and final stages of the anoxic process and the middle and final stages of the oxic process (Fig. 1).

Analytical methods Generally, the values of $\mathrm{pH}$, suspended solids (SS), chemical oxygen demand (COD), biochemical oxygen demand (BOD), total organic carbon (TOC), alkalinity, total nitrogen (T-N), $\mathrm{NH}_{4}-\mathrm{N}, \mathrm{NO}_{2}-\mathrm{N}, \mathrm{NO}_{3}-\mathrm{N}$, total phosphate (T-P), and $\mathrm{PO}_{4}-\mathrm{P}$ were measured for the influent and the effluent. The values of MLSS, mixed liquor volatile suspended solids (MLVSS), and sludge volume (SV) were measured for the activated sludge. The excess sludge was intermittently drawn out from the reactor in order to control the 
MLSS at a value of $2500 \mathrm{mg} / l$. The values of TOC, $\mathrm{NH}_{4}-\mathrm{N}, \mathrm{NO}_{2}-\mathrm{N}, \mathrm{NO}_{3}-\mathrm{N}, \mathrm{PO}_{4}-\mathrm{P}, \mathrm{pH}, \mathrm{DO}$, and oxidation-reduction potential (ORP) in the SBR were measured at many points during one cycle.

Most of the qualities of the influent, the effluent, and the activated sludge were analyzed by the standard methods for wastewater ${ }^{11)}$. The TOC was measured by a TOC analyzer (Shimadzu Co., Kyoto Japan, TOC5000). The $\mathrm{NH}_{4}-\mathrm{N}, \mathrm{NO}_{2}-\mathrm{N}, \mathrm{NO}_{3}-\mathrm{N}$, and $\mathrm{PO}_{4}-\mathrm{P}$ were measured by an ion chromatograph (Dionex Co., USA, DX120). The DO meter was the YSI MODEL 58 (Yellow Springs Instrument $\mathrm{Co}_{0}$., Inc., USA).

\section{RESULTS AND DISCUSSION}

\section{Characteristics of reactions in the SBR}

The qualities of the effluent in each Run are shown in Table 2. Usually, no $\mathrm{NH}_{4}-\mathrm{N}$ was detected, and the concentration of TOC was $8 \mathrm{mg} / l$ or less. Therefore, it was confirmed that the effluent became an advanced treatment water. The variation of DO with time during one cycle for each Run is shown in Fig. 2. The concentration of DO was about $0.3 \mathrm{mg} / l$ to the stage of three-fourths of the oxic process. In other words, during this period the oxygen supplied in the SBR was consumed for the degradation of organic matter and the nitrification. After that the concentration of DO rapidly increased. This behavior seems to indicate that the degradation of organic matter by the heterotrophic bacteria and the nitrification have ended. After these reactions were completed, the oxygen was accumulated in the aqueous solution, and resulting in the increase of the concentration of DO. This behavior was observed in all the Runs.

In this study, the TOC was used as the index for organic matter in the SBR. The variation of TOC, $\mathrm{NO}_{3}-\mathrm{N}$, and $\mathrm{NH}_{4}-\mathrm{N}$ with time in the SBR for each Run is shown in Fig. 3. No $\mathrm{NO}_{2}-\mathrm{N}$ was detected in any Run. It was confirmed that about $50 \%$ or more of TOC was removed at the beginning of the anoxic process. This was attributed to that the TOC was adsorbed on the activated sludge and used to denitrification reaction. The $\mathrm{NO}_{3}-\mathrm{N}$ rapidly decreased at the beginning of the anoxic process. This was due to denitrification by degradable organic matter acting as a hydrogen donor. Then, the remaining TOC was gradually decomposed, so that $60-80 \%$ of the initial TOC was removed at the end of the anoxic process. On the other hand, during the anoxic process, the $\mathrm{NH}_{4}-\mathrm{N}$ did not decrease. In the following oxic process about $20 \%$ of TOC was degraded.

For the activated sludge acclimated under the control system (Run 1), nitrification could be achieved within the preset time of $4.5 \mathrm{~h}$ by

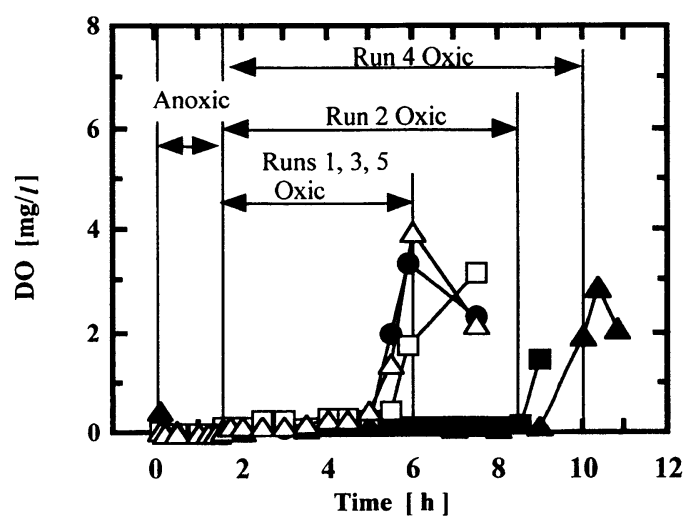

Fig. 2 Variation of DO in a cycle in the SBR for each run.

Symbols : $\bigcirc$, Run 1; $\square$, Run 2; $\square$, Run 3 $\boldsymbol{\Delta}$, Run 4; and $\triangle$, Run 5 .

Table 2 Qualities of effluent

\begin{tabular}{ccccccccc}
\hline Run No. & $\begin{array}{c}\mathrm{pH} \\
{[-]}\end{array}$ & $\begin{array}{c}\mathrm{TOC} \\
{[\mathrm{mg} / l]}\end{array}$ & $\begin{array}{c}\mathrm{T}-\mathrm{N} \\
{[\mathrm{mg} / l]}\end{array}$ & $\begin{array}{c}\mathrm{NH}_{1}-\mathrm{N} \\
{[\mathrm{mg} / l]}\end{array}$ & $\begin{array}{c}\mathrm{NO}_{2}-\mathrm{N} \\
{[\mathrm{mg} / l]}\end{array}$ & $\begin{array}{c}\mathrm{NO}_{3}-\mathrm{N} \\
{[\mathrm{mg} / l]}\end{array}$ & $\begin{array}{c}\mathrm{T}-\mathrm{P} \\
{[\mathrm{mg} / l]}\end{array}$ & $\begin{array}{c}\mathrm{PO}_{4}-\mathrm{P} \\
{[\mathrm{mg} / l]}\end{array}$ \\
\hline 1 & 6.96 & 7.5 & 11.5 & 0.4 & $\mathrm{ND}$ & 9.0 & 2.8 & 2.4 \\
2 & 6.36 & 7.1 & 18.6 & $\mathrm{ND}$ & $\mathrm{ND}$ & 17.3 & 3.0 & 2.0 \\
3 & 6.39 & 7.0 & 19.5 & $\mathrm{ND}$ & $\mathrm{ND}$ & 18.3 & 2.9 & 2.1 \\
4 & 6.54 & 5.4 & 16.3 & $\mathrm{ND}$ & $\mathrm{ND}$ & 16.6 & 2.9 & 2.2 \\
5 & 6.73 & 6.5 & 14.6 & 0.2 & $\mathrm{ND}$ & 14.4 & 1.5 & 1.5 \\
\hline
\end{tabular}




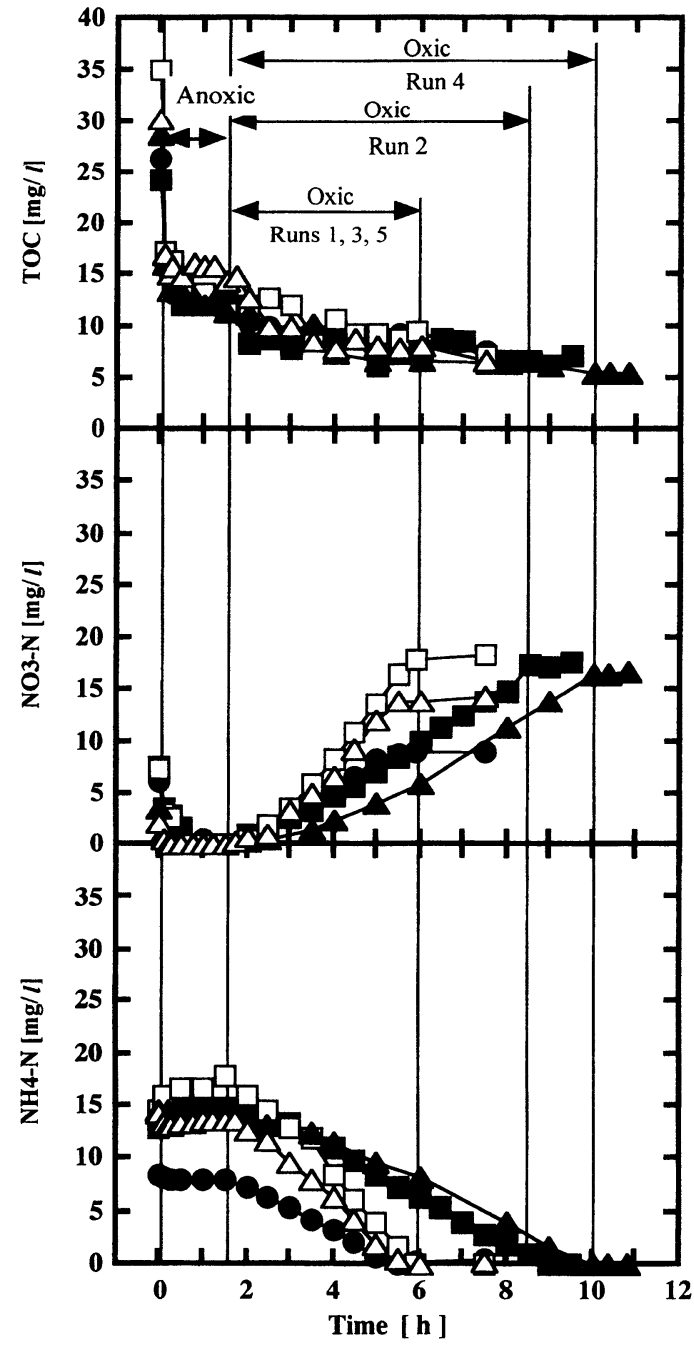

Fig. 3 Variation of TOC, $\mathrm{NO}_{3}-\mathrm{N}$ and $\mathrm{NH}_{4}-\mathrm{N}$ in a cycle in the SBR for each run.

Symbols : $\bigcirc$, Run $1 ; \square$, Run 2; $\square$, Run 3 ; $\boldsymbol{\Delta}$, Run 4 ; and $\triangle$, Run 5.

increasing the flow rate of air, even when the ratio of the influent fed in the SBR was temporarily doubled for Run 5 . The rate of nitrification was $0.88 \mathrm{mg} / \mathrm{h} \cdot \mathrm{g}-\mathrm{MLSS}$ in the control system. On the contrary, the rate for Run 5 increased to $1.35 \mathrm{mg} / \mathrm{h} \cdot \mathrm{g}$-MLSS. This increase in the rate of nitrification for Run 5 suggests that the degradation of organic matter and the nitrification simultaneously occurred at an increased flow rate of air. It was found that the application of the anoxic process was effective for reducing the amount of organic matter, because the organic matter was used for denitrification. Therefore, the oxygen was advantageously used for nitrification in the following oxic process.

Conditions of OUR in the SBR The value of OUR was found to change greatly with concentrations of organic matter and $\mathrm{NH}_{4}-\mathrm{N}$ included in the mixed liquor. The data points of DO vs. time did not always fall on a straight line in the entire region. Typical consuming curves of DO vs. time are shown in Fig. 4. Generally, the consuming curve of DO vs. time is considered to be linear, and the value of OUR is calculated from the gradient of the curve for the whole range of DO. However, the consuming curves of DO obtained in this study were not straight as described above. Therefore, the values of TOUR, COUR, and NOUR are plotted vs. the values of DO in Fig. 5. The stable values of OURs in the DO range from 1.5 to $2.5 \mathrm{mg}-\mathrm{O} / \mathrm{l}$ could be obtained. Therefore, the values of TOUR, COUR, and NOUR were calculated for this DO range (1.5$2.5 \mathrm{mg}-\mathrm{O} / l$ ).

For the activated sludge, the values of TOUR, COUR, and NOUR measured at four points of the initial and final stages of the anoxic process and the middle and final stages of the oxic process in the SBR are shown in Fig. 6. The values of TOUR and COUR decrease linearly with the measurement points with the exception of the data of Run 5 for COUR.

In Fig. 6 the values of TOUR includes the value of COUR, which is necessary for degradation of organic matter, and NOUR, which is necessary for nitrification. In the anoxic process, only organic matter was used as the hydrogen donor for denitrification. Then, the organic matter left after denitrification was decomposed in the oxic process. The value of COUR decreased with degradation of organic matter as shown in Figs. 3 and 6. In Fig. 6 the value of NOUR was almost constant until the middle stage of oxic process. Therefore, it is considered that the decrease of TOUR is attributed to the decrease of COUR. However, the value of NOUR rapidly decreased at the end stage of the oxic process. When the concentration of $\mathrm{NH}_{4}-\mathrm{N}$ was high, the respiratory activity of nitrifying bacteria was kept high. However, 


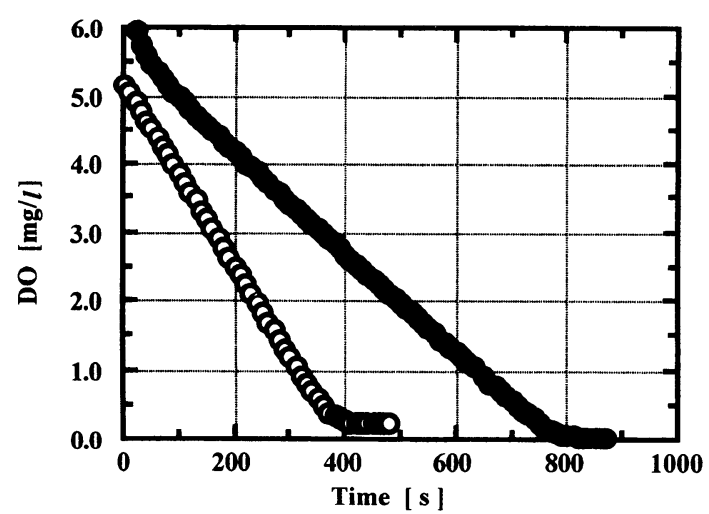

Fig. 4 Example DO consumption curves showing variation.

Symbols : $\bigcirc$, No ATU addition and

, ATU addition.

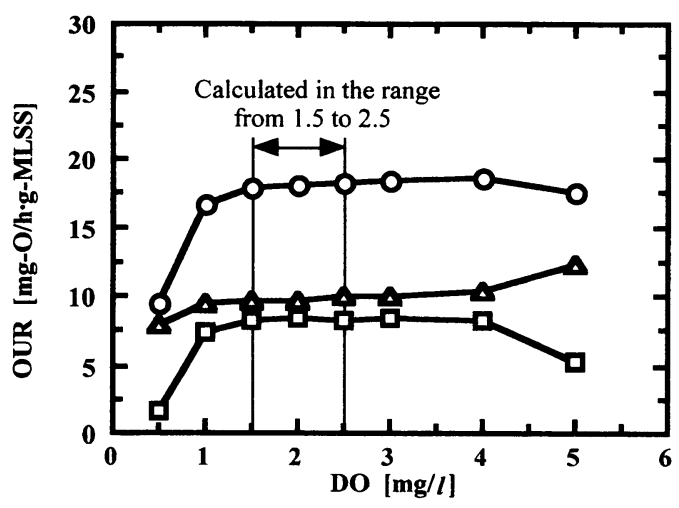

Fig. 5 Relationship between DO and OUR. Symbols : $O$, TOUR; $\triangle$, COUR; and , NOUR.

when the concentration of $\mathrm{NH}_{4}-\mathrm{N}$ was very low, the respiration activity quickly dropped.

The values of COUR for the concentration of TOC and the values of NOUR for the concentration of $\mathrm{NH}_{4}-\mathrm{N}$ were plotted in Figs. 7 and 8 , respectively. Generally, it is known that the amount of bacteria existing in the activated sludge is abundant. The value of OUR is expected to change with the concentration of organic matter. In Fig. 7 it was found that there is a strong correlation between COUR and TOC, which could be represented by the following equation:

$$
\mathrm{Y}=1.4598+0.3413 \mathrm{x} \quad \mathrm{R}=0.84
$$

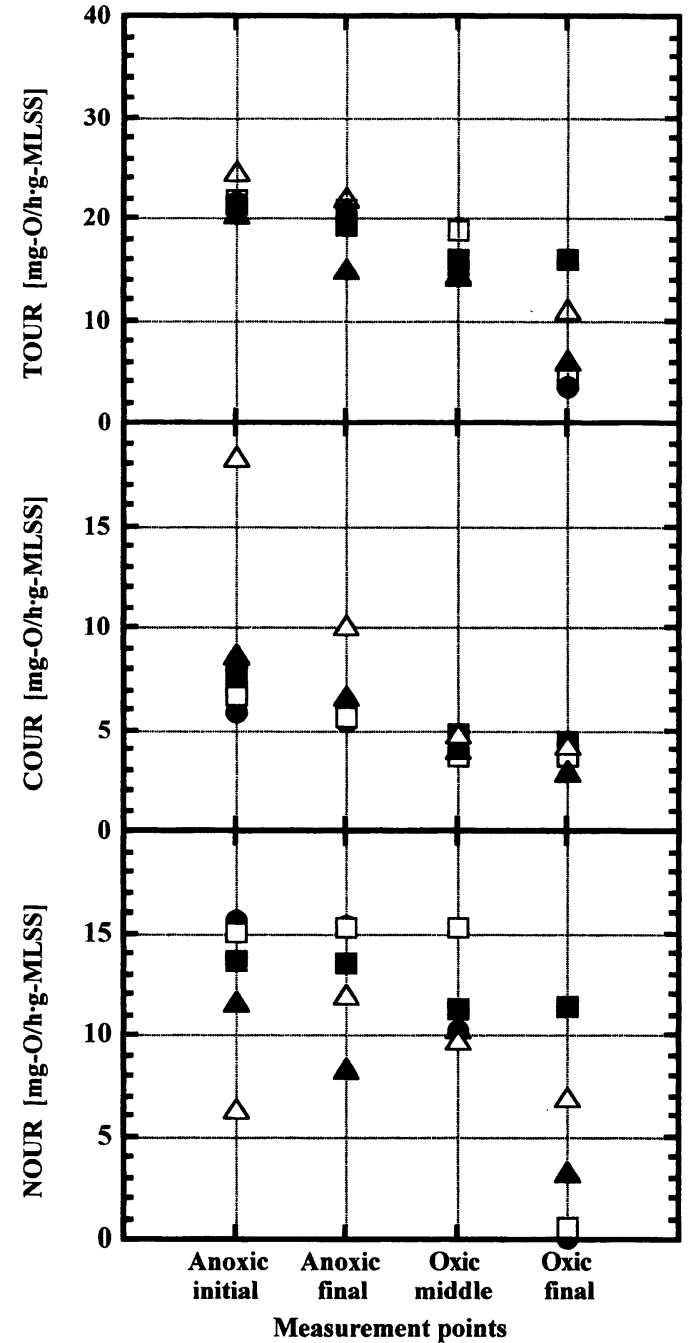

Fig. 6 Variation of TOUR, COUR and NOUR at each measurement point in the SBR. Symbols :

. Run 1; Run 2; $\square$, Run 3 ; $\boldsymbol{\Delta}$, Run 4; and $\triangle$, Run 5 .

where $\mathrm{Y}$ is COUR [mg-O/h.g-MLSS] and $\mathrm{x}$ TOC $[\mathrm{mg} / \mathrm{l}]$.

The correlation coefficient $(R)$ was a reasonable value of 0.84 , and it was possible to estimate the concentration of TOC included in the activated sludge by measuring the value of COUR. On the other hand, in Fig. 8 the relation between the value of NOUR and the concentration of $\mathrm{NH}_{4}-\mathrm{N}$ showed that the values of NOUR were scattered from 5 to $15 \mathrm{mg}-\mathrm{O} / \mathrm{h} \cdot \mathrm{g}-\mathrm{MLSS}$ in the range of a $3 \mathrm{mg} / \mathrm{l}$ or more of $\mathrm{NH}_{4}-\mathrm{N}$. However, when the concen- 


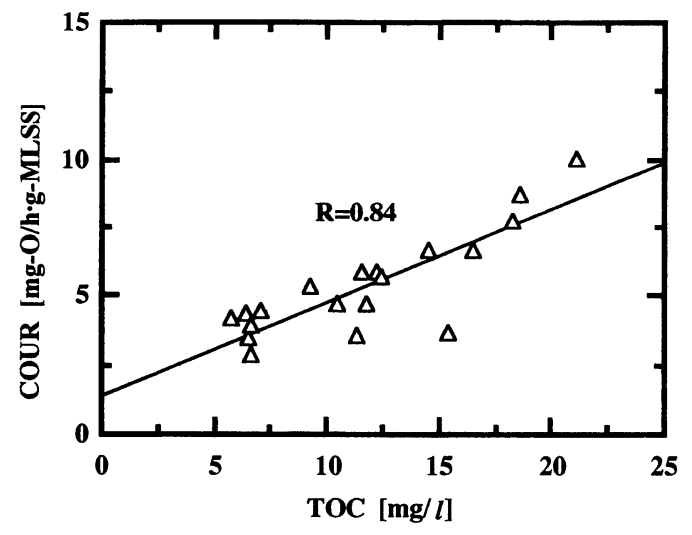

Fig. 7 Relationship between TOC and COUR.

tration of $\mathrm{NH}_{4}-\mathrm{N}$ was $2 \mathrm{mg} / l$ or less, the value of NOUR was $3 \mathrm{mg}-\mathrm{O} / \mathrm{h} \cdot \mathrm{g}-\mathrm{MLSS}$ or less. These experimental results agreed well with the results reported by Surmcz-Gorska et $a l .^{9}$. Generally, the presence of $\mathrm{NH}_{4}-\mathrm{N}$ in the effluent causes a significant problem in the advanced wastewater treatment process. From the above discussion, it was proved that the use of NOUR was very effective for making a simple and easy judgement on the presence of $\mathrm{NH}_{4}-\mathrm{N}$ in the effluent.

\section{CONCLUSIONS}

Experiments were carried out by using actual domestic wastewater as the influent in the SBR. An estimation method for the degradation characteristics of organic matter and the nitrification conditions was proposed by measuring OUR in the SBR. Two kinds of OURs : TOUR and COUR were measured simultaneously. The COUR was measured in the presence of ATU as a nitrification inhibitor. The value of NOUR was calculated by subtracting COUR from TOUR. The COUR could be used to estimate the concentration of TOC for the activated sludge in the SBR, and the NOUR was very effective for examining the presence of $\mathrm{NH}_{4}-\mathrm{N}$ in the effluent.

\section{REFERRENCES}

1 ) Spanjers H., Olsson G., and Klapwijk A. : Determining short-term biochemical

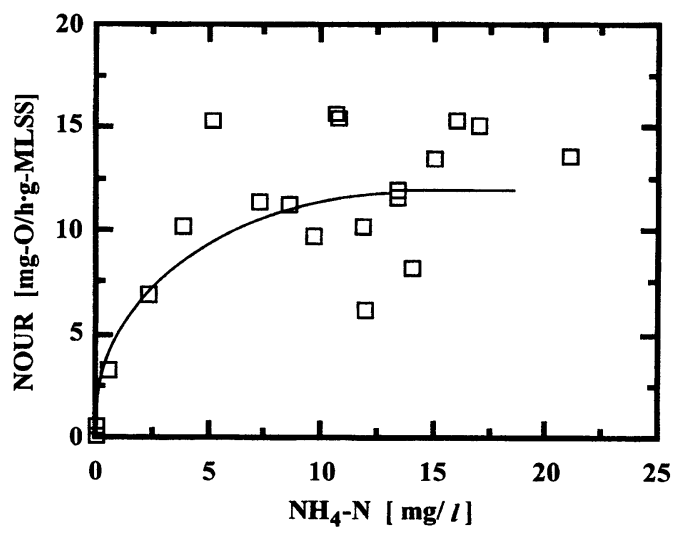

Fig. 8 Relationship between $\mathrm{NH}_{4}-\mathrm{N}$ and NOUR.

oxygen demand and respiration rate in an aeration tank by using respirometry and estimation. Wat. Res. 28, 1571-1583 (1994)

2) $\mathrm{Xu}$ S., and Hasselblad S. : A simple biological method to estimate the readily biodegradable organic matter in wastewater. Wat. Res. 30, 1023-1025 (1996)

3 ) Kong Z., Vanrolleghem P., Willems P., and Vrestraete W. : Simultaneous determination of inhibition kinetics of carbon oxidation and nitrification with a respirometer. Wat. Res. 30, 825-836 (1996)

4 ) Ossenbruggen p. J., Spanjers H., and Klapwik A. : Assessment of a two-step nitrification model for activated sludge. Wat. Res. 30, 939-953 (1996)

5 ) Klapwijk A., Brouwer H., Vrolijk E., and Kujawa K. : Control of intermittently aerated nitrogen removal plants by detection endpoints of nitrification and denitrification using respirometry only. Wat. Res. 32, 1700-1703 (1998)

6 ) Ubay Ç. E., Sözen S., Orhon D., and Henze M. : Respirometric analysis of activated sludge behaviour- I. Assessment of the readily biodegradable substrate Wat. Res. 32, 461-475 (1998)

7 ) Sözen S., E. Ubay C. E., Orhon D., and Henze M. : Respirometric analysis of activated sludge behaviour-II . Heterotrophic growth under aerobic and 
anoxic conditions Wat. Res. 32, 476-488 (1998)

8 ) Brouwer H., Klapwijk A., and Keesman K. J. : Identification of activated sludge and wastewater characteristics using respirometric batch-experiments. Wat. Res. 32, 1240-1254 (1998)

9 ) Surmcz-Gorska J., Gernay K., Demuynck C., Vanrolleghem P., and Verstraete W. : Nitrification monitoring in activated sludge by oxygen uptake rate (OUR) measurement. Wat. Res. 30, 1228-1236
(1996)

10) Suescum J., Irizar I., Ostolaza X., Ayesa E. : Dissolved oxygen control and simultaneous estimation of oxygen uptake rate in activated-sludge plants. Wat. Environ. Res. 70, 316-322 (1998)

11) Japan Sewage Works Assoc. : Standard method for the examination of wastewater (1996) (in Japanese)

(Submitted 2000. 7. 6)

(Accepted 2000. 9. 26) 